\title{
EXERCÍCIO ILEGAL DA ORTODONTIA E SUAS CONSEQUÊNCIAS CLÍNICAS \\ - relato de caso
}

\author{
Marice Almeida Pereira*, Flávia Menezes de Souza*, Pâmela Almeida de Queiroz**, Deyla Duarte \\ Carneiro Vilela***, Juliana Andrade Cardoso****

\footnotetext{
Autor correspondente: Juliana Andrade Cardoso - juliandradec@gmail.com

*Graduanda em Odontologia pela União Metropolitana de Educação e Cultura, Lauro de Freitas, Bahia

**Graduanda em Odontologia pela Faculdade de Tecnologia e Ciências, Salvador, Bahia

*** Mestre em Odontologia - Estomatologia pela Escola Bahiana de Medicina e Saúde Pública. Professora do Núcleo de Propedêuticas da União Metropolitana de Educação e Cultura, Lauro de Freitas, Bahia

****Mestre em Estomatologia Clínica pela Pontifícia Universidade Católica do Rio Grande do Sul. Professora do núcleo de Propedêuticas da União Metropolitana de Educação e Cultura, Lauro de Freitas, Bahia
}

\begin{abstract}
Resumo
Introdução: O número de pacientes adultos que procuram o tratamento ortodôntico tem aumentado sensivelmente nos últimos anos, no entanto, a instalação de aparelhos ortodônticos falsos, realizada por conta própria, sem o mínimo de conhecimento especializado e dos prejuízos que podem trazer à saúde bucal tem tomado conta do país. Objetivo: Relatar um caso clínico de um paciente do sexo masculino, 42 anos, que fazia uso de aparelho ortodôntico de procedência incerta. O paciente apresentava higiene bucal precária, mobilidade grau III em diversas unidades, e foi encaminhado para realizar extrações múltiplas, com posterior reabilitação. Discussão: Os aparelhos ortodônticos utilizados pelos ortodontistas são rigorosamente supervisionados pela ANVISA. São fabricados com materiais biocompatíveis e seus fios possuem forças especificamente calibradas e formatos adequados à arcada dental para movimentar os dentes. Os acessórios piratas, sem nota fiscal e sem origem de fabricação são encontrados na maioria das vezes com vendedores ambulantes. Os materiais para confecção destes aparelhos, como elásticos, borrachas e fios dentários são comercializados nas ruas ou por usuários nas redes sociais. Muitas vezes, a aplicação inclui fios de vassoura e supercola, além de fios e elásticos trançados. São materiais sem qualquer tipo de controle que podem causar intoxicações, alergias severas e alterações periodontais ou dentárias. Considerações finais: É de fundamental importância que os dentistas tomem conhecimento dessa nova moda que vem sendo adotada pelos jovens a fim de conscientizá-los dos riscos que estão submetidos ao adotar o uso desnecessário do aparelho ortodôntico sem a devida supervisão do profissional especializado.
\end{abstract}

Palavras-chave: Ortodontia; Movimentação Dentária; Charlatanismo. 


\title{
ILLEGAL PRACTICE OF ORTHODONTICS EXERCISING AND ITS CLINICAL IMPLICATIONS
}

\author{
- case report •
}

\begin{abstract}
Introduction: The number of adult patients looking for orthodontic treatment has markedly increased in recent years. However, fake orthodontic appliance use, performed without minimum expertise or knowledge of the damage that it may cause to oral health, became very common in Brazil. Objective: To report the case of a male patient, 42 years old, who used an orthodontic appliance of uncertain origin. The patient had poor oral hygiene and grade III mobility in several units, and was referred to perform multiple extractions, with subsequent rehabilitation. Discussion: Orthodontic appliance used by orthodontists are strictly supervised by ANVISA. They are manufactured from biocompatible materials and their wires have specifically calibrated forces and appropriate formats to the dental arch, in order to move the teeth. Pirate accessories, without invoice and manufacturing origin, are usually found with street salesman. Materials used to make these devices, such as elastic bands, rubbers and dental yarns, are sold on the streets or in social networks. Often, application includes broom wires and superglue, in addition to twisted wires and elastic bands. These materials do not have any type of control and may cause poisoning, severe allergies and periodontal or dental changes. Final considerations: It is vital to dentists to be aware of this new fashion that has been adopted by young people, in order to make them aware of the risks they are subjected when adopting unnecessary use of dental appliance, without due supervision of specialized personnel.
\end{abstract}

Keywords: Orthodontics; Tooth Movement; Quackery.

\section{INTRODUÇÃO}

O número de pacientes adultos que procuram tratamento ortodôntico tem aumentado sensivelmente nos últimos anos, no entanto, a necessidade de plano de tratamento e mecânicas mais complexas também aumentou, sendo mais frequentes os casos de pacientes ortodônticos portadores de doenças periodontais com perdas de inserção.(1) Além disso, os acessórios ortodônticos colados nas superfícies dentárias dificultam a higienização e funcionam como retentores adicionais de biofilme dental, constituindo a base para um risco elevado de cárie dentária e periodontite. ${ }^{(2)}$

A periodontite crônica é uma das doenças periodontais mais frequentes, com alta prevalência em adultos e, acomete principalmente indivíduos com higiene bucal deficiente. ${ }^{(3,4)}$ Corresponde a inflamações crônicas e progressivas, caracterizadas clinicamente por inflamação gengival, sangramento à sondagem, diminuição da resistência dos tecidos periodontais à sondagem (bolsas periodontais), perda de inserção gengival e reabsorção do osso alveolar. ${ }^{(5)}$

Nos últimos meses, uma nova moda que vem sendo adotada pelos adolescentes e se disseminando através das redes sociais, tem assustado e mobilizado a sociedade odontológica brasileira. Os jovens estão colocando aparelhos ortodônticos por conta própria, ou com ajuda de amigos e leigos, sem o mínimo de conhecimento especializado e nem dos prejuízos que podem trazer à saúde bucal. 
O presente trabalho tem como objetivo relatar um caso clínico de um paciente que procurou atendimento odontológico para exodontia de uma unidade dentária e, ao exame intraoral foi observada além da higiene bucal precária, uso indevido de aparelho ortodôntico, sendo este de procedência incerta. Este trabalho visa ainda mostrar essa nova moda que vem tomando conta dos jovens, para que os cirurgiões-dentistas saibam reconhecer os aparatos ortodônticos piratas e orientar os pacientes da melhor forma, bem como conscientizá-los dos riscos que estão submetidos ao adotar o uso desnecessário do aparelho ortodôntico sem a devida supervisão do profissional especializado.

\section{RELATO DE CASO}

Paciente melanoderma, gênero masculino, 42 anos de idade procurou atendimento odontológico para exodontia de uma unidade dentária. Após assinatura do Termo de Consentimento Livre e Esclarecido procedeu-se com anamnese e exame extraoral cuja alterações não foram identificadas.

Ao exame intrabucal foi observada higiene precária associada ao uso de aparelho ortodôntico falso confeccionado com fios de nylon, além de mobilidade grau III em diversas unidades (figuras $1 \mathrm{~A}$, $\left.{ }_{1 \mathrm{~B}},{ }_{1} \mathrm{C}\right)$.
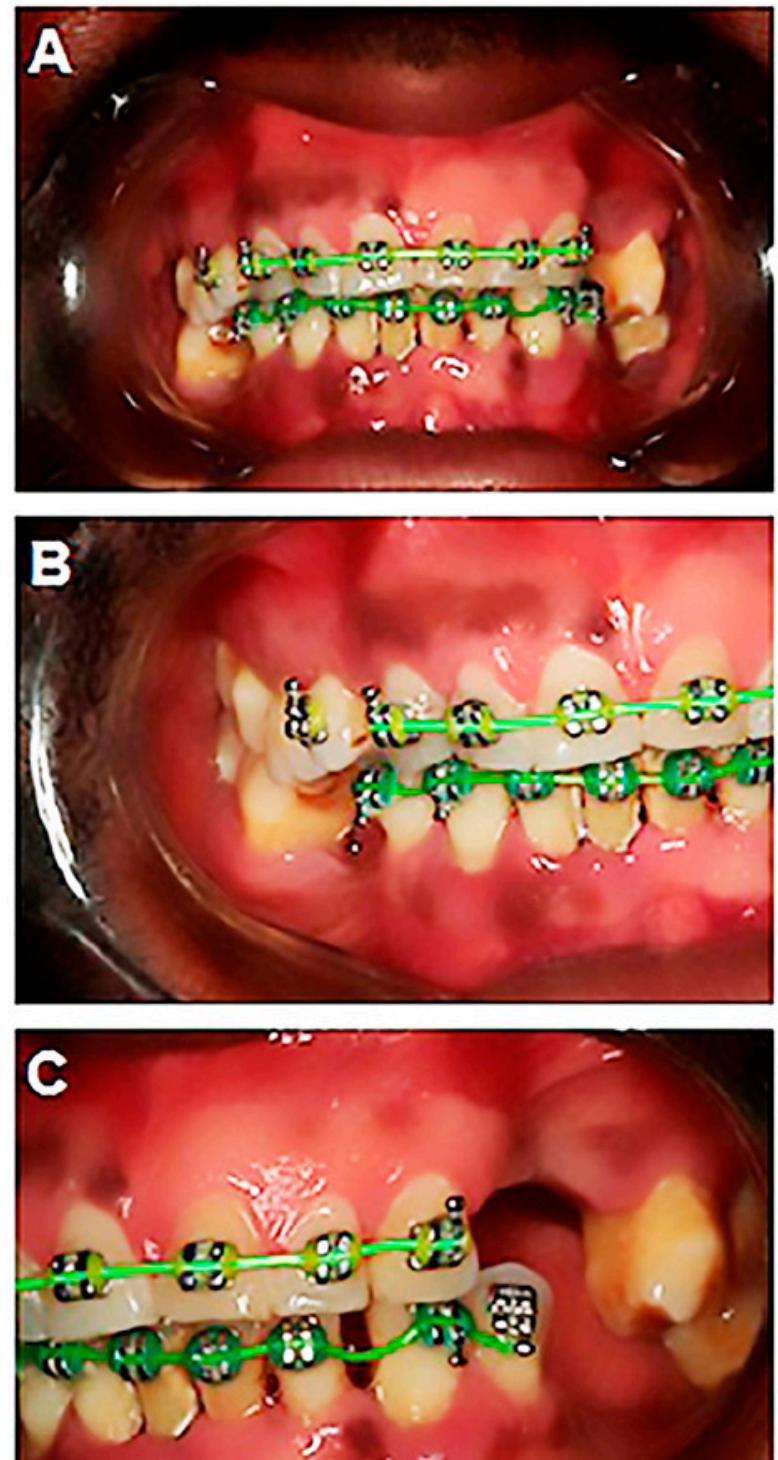

Figura 1 - A) Aspecto clínico intrabucal. Observa-se presença de aparato ortodôntico inadequado, confeccionado com fios de nylon. B) Aspecto clínico intrabucal lado direito. C) Aspecto clínico intrabucal lado esquerdo 
Radiografias periapicais e panorâmica foram realizadas, comprovando perda óssea generalizada, bem como a ausência do fio ortodôntico (figuras 2 e 3). A radiografia panorâmica evidenciou além da ausência das unidades 14, 24, 25, 26, 35, 36, 37, 45 e 46, unidades 16 e 27 em supraoclusão, unidade 28 com reabsorção óssea severa, unidades 38,47 e 48 mesializadas e com comprometimento de furca.

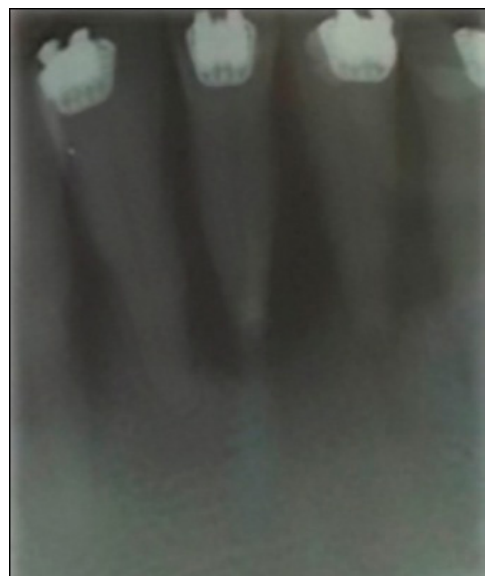

Figura 2 - Radiografia periapical da região de incisivos inferiores comprovando perda óssea severa e ausência do fio ortodôntico

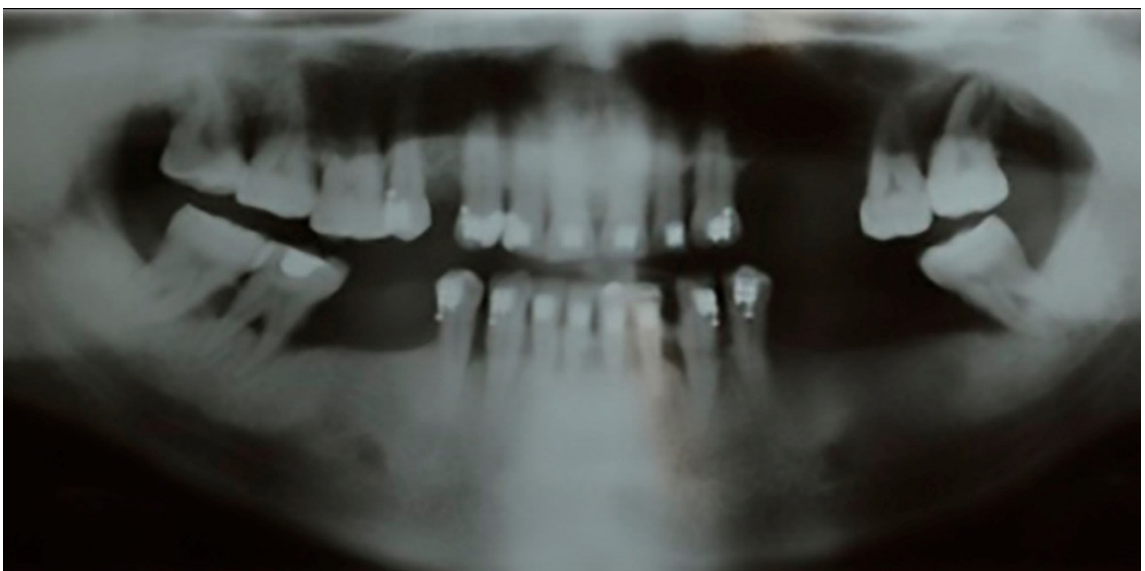

Figura 3 - Radiografia panorâmica em topo evidenciando perda óssea generalizada, ausência do fio ortodôntico, ausência das unidades 14, 24, 25, 26, 35, 36, 37, 45 e 46, unidades 16 e 27 em supraoclusão, unidade 28 com reabsorção óssea severa, unidades 38,47 e 48 mesializadas e com comprometimento de furca
O paciente foi encaminhado para avaliação periodontal e após a realização do periograma foi diagnosticado com periodontite crônica generalizada severa. O plano de tratamento proposto foi a remoção do aparato ortodôntico, raspagem e alisamento radicular de todas as unidades, exodontias das unidades 31, 32, 33, 34, 38, 41, 42, 43, 44, $47 \mathrm{e}$ 48 assim como uma posterior reabilitação protética com prótese total para arcada inferior e para substituir as unidades superiores ausentes será feita prótese parcial removível. No entanto, até o momento o paciente continua fazendo uso do aparato ortodôntico, pois o mesmo não comparece às consultas marcadas para dar continuidade ao tratamento.

\section{DISCUSSÃO}

Nos últimos anos houve uma grande procura de tratamento ortodôntico por parte dos pacientes adultos, o que despertou um interesse do comércio informal. ${ }^{(6)} \mathrm{O}$ aparelho ortodôntico corretamente posicionado, corrige a posição dos dentes desalinhados e desnivelados nos ossos maxilares através de determinada força, sob supervisão constante do profissional. Para o sucesso do tratamento ortodôntico, porém, faz-se necessário um plano de tratamento bem elaborado.(1)

Os chamados "aparelhos personalizados", "aparelhos falsos" ou "aparelhos piratas" vêm sendo bastante utilizados por um grande número de pessoas, sem o acompanhamento de um profissional especializado na área. Estes estão sendo vendidos sem fiscalização, ilegalmente no país, por pessoas inabilitadas, sem conhecimento científico algum e o Conselho Federal de Odontologia tem se mobilizado para coibir casos do exercício ilegal da odontologia configurados pela venda de produtos e instalação de aparelhos no comércio informal. ${ }^{(6)}$

Os aparelhos ortodônticos utilizados pelos cirurgiões-dentistas especialistas em Ortodontia são rigorosamente supervisionados pela Agência Nacional de Vigilância Sanitària (Anvisa) quando nacionais e, submetidos a importantes órgãos reguladores 
quando importados. São fabricados com materiais biocompatíveis e seus fios possuem forças especificamente calibradas e formatos adequados à arcada dental para movimentar os dentes, diferente dos aparelhos falsos que vem sendo comercializados. ${ }^{(6,7)}$

Os acessórios piratas, sem nota fiscal e sem origem de fabricação são encontrados na maioria das vezes com vendedores ambulantes. Os materiais para confecção destes aparelhos, como elásticos, borrachas e fios de nylon são comercializados nas ruas ou por usuários nas redes sociais e em sites. Muitas vezes, a aplicação inclui fios de vassoura e supercola, além de fios elásticos. São materiais sem qualquer tipo de controle, que podem causar intoxicações, alergias severas e alterações periodontais ou dentárias. Outro tipo de material ortodôntico utilizado é o elástico corrente que causa uma movimentação dentária mais acentuada e deve ser usado para casos específicos necessitando de um acompanhamento mais rigoroso do cirurgião-dentista, porém isso também tem sido negligenciado. ${ }^{(6)} \mathrm{O}$ presente caso relatado trata-se de mais uma vítima da comercialização ilegal de produtos odontológicos em nosso país.

Por se tratar de um requisito de tamanha importância, a legislação federal impõe como infração sanitária a comercialização de tais produtos sem a devida autorização, assim como também infringe a norma sanitária, o profissional da área que compra materiais em casas dentárias irregulares. ${ }^{(6)}$

O paciente foi encaminhado para realização de exames como odontograma, periograma e exame de oclusão, bem como realização de radiografias periapicais e panorâmica. Foi diagnosticado com periodontite crônica generalizada severa e orientado para remoção do aparato ortodôntico para dar início ao tratamento, uma vez que a literatura afirma que o tratamento ortodôntico realizado de uma forma inadequada em pacientes periodontais, pode certamente contribuir para futuro colapso dos tecidos de suporte periodontal. ${ }^{(1,8,9)}$

As consequências variáveis da doença periodontal incluem hiperplasia ou recessão gengival, exposição da furca, mobilidade e inclinação dentárias aumentadas e perda de estrutura de sustentação dos dentes. Possuem como etiologia primária a presença de bactérias específicas residentes no biofilme dentário, associada à deficiência no mecanismo de defesa do paciente. ${ }^{(5)}$ Sua prevenção evita a perda dentária futura, além do agravo de doenças sistêmicas que podem estar associadas à periodontopatias. ${ }^{(4)}$

A progressão da periodontite crônica é um processo contínuo que sofre períodos de exacerbação aguda.(5) Até o presente, a periodontite tem seu diagnóstico basicamente direcionado por parâmetros clínicos e história da doença. Frequentemente, esse diagnóstico só é estabelecido a partir do momento em que já há dano e perda tecidual instalada.(4) As terapias utilizadas incluem a remoção da placa supra e subgengival, motivação e habilidade do paciente no cuidado diário, terapia de manutenção, e quando necessário, uso de substâncias com ação farmacológica comprovada cientificamente. ${ }^{(5)}$

A literatura evidencia que o sucesso do tratamento periodontal para obtenção de bons resultados centraliza-se na conversão do local com periodontite ativa para o estado inativo, mesmo que o periodonto encontre-se reduzido, sem que isso signifique mais deteorização do tecido de sustentação, ${ }^{(1)}$ o que justifica a necessidade de remoção do aparato ortodôntico para o início do tratamento odontológico.

Além do uso indevido do aparelho ortodôntico, o paciente do presente caso apresentava ainda higiene oral muito insatisfatória, o que pode ter exacerbado a doença periodontal que já se encontrava instalada, uma vez que a literatura comprova que os acessórios ortodônticos colados nas superfícies dentárias dificultam a higienização e funcionam como retentores adicionais de biofilme bacteriano, levando à desmineralização do esmalte, causando mancha branca e gengivites. ${ }^{(2)}$

O risco no uso de aparelhos ortodônticos falsos, usando forças sem parâmetros de direção, intensidade e quantidade, faz com que o dente se movimente aleatoriamente no osso, causando perda nas estruturas periodontais que dão suporte os 
dentes, ferimentos gengivais e perda das unidades dentárias. O uso de cola tóxica para fixação do aparelho pode causar lesões na mucosa bucal. ${ }^{(6,7)}$

O plano de tratamento elaborado para este caso foi remoção do aparelho ortodôntico falso, raspagem e alisamento radicular de todas as unidades presentes, exodontia das unidades $31,32,33,34,38,41,42,43,44,47$ e 48 assim como uma posterior reabilitação protética com prótese total para arcada inferior e para substituir as unidades superiores ausentes será feita prótese parcial removível. No entanto, o paciente não contribuiu com o tratamento, ausentando-se às diversas sessões clínicas, e continua mantendo o uso do aparelho ortodôntico indevidamente.

\section{CONSIDERAÇÕES FINAIS}

É de fundamental importância que os cirurgiõesdentistas tomem conhecimento dessa moda que vem tomando conta dos jovens para saber reconhecer os aparatos ortodônticos piratas, orientar os pacientes e conscientizá-los dos riscos que estão submetidos ao adotar o uso desnecessário do aparelho ortodôntico sem a devida supervisão do profissional especializado, o que se torna fundamental na redução das sequelas.

\section{REFERÊNCIAS}

1. Calheiros A, Fernandes A, Quintão CA, Souza EV. Movimentação ortodôntica em dentes com comprometimento periodontal: relato de um caso clínico. Rev Dent Press Ortodon Ortopedi Facial. 2005;10(2):111-8.

2. Olympo KPK, Bardal PAP, Henriques JFC, Bastos JRM. Prevenção de cárie dentária e doença periodontal em Ortodontia: uma necessidade imprescindível. Rev Dent Press Ortodon Ortopedi Facial. 2006;11(2):110-9.

3. Vieira TR, Péret ACA, Péret Filho LA. Alterações periodontais associadas às doenças sistêmicas em crianças e adolescentes. Rev Paul Pediatr. 2010;28(2):237-43.

4. Naiff PF, Orlandi PP, Santos MC. Imunologia da periodontite crônica: uma revisão de literatura. Scientia Amazonia. 2012;1(2):28-36.

5. Nuto SAS, Nations MK, Costa ICC. Aspectos culturais na compreensão da periodontite crônica: um estudo qualitativo. Cad Saúde Pública. 2007; 23(3):681-90.

6. CROBA. Fiscalização - Conselho alerta para a comercialização ilegal de produtos Odontológicos. Revista Trimestral do Conselho Regional de Odontologia da Bahia. 2O14; 4(8):10.

7. Santos PR. Aparelhos ortodônticos piratas estão virando moda entre os jovens, pode resultar na perda dos dentes. 2014 [citado 2015 fev. 15]. Disponível em: 〈www.apcd.org.br>.

8. Gkantidis N, Christou P, Topouzelis N. The orthodontic-periodontic interrelationship in integrated treatment challenges: a systematic review. J Oral Rehabil. 2010;37:377-90.

9. Laino A, Melsen B. Orthodontic treatment of a patient multidisciplinary problems. Am J Orthod Dentofacial Orthop. 1997;111(2):141-8. 